\title{
REMOTE PRACTICAL ANATOMY CLASSES: NEW CHALLENGES AND DIRECTIONS FOR TUTORS
}

\author{
Dzintra Kazoka \\ Rīga Stradiņš University, Institute of Anatomy and Anthropology, Latvia \\ Mara Pilmane \\ Rīga Stradiņš University, Institute of Anatomy and Anthropology, Latvia
}

\begin{abstract}
Human Anatomy tutors had to adapt to Covid-19 reality by restructuring their methods by teaching in spring - autumn in 2020 at the Department of Morphology. The aims of this study were to identify and understand the variety of solutions being utilized by tutors and to clarify new challenges and directions. The open-ended interviews were used to collect data from 15 Anatomy tutors. Thematic analysis, used to analyze the qualitative data, emphasized the tutors' perceptions of remote practical anatomy classes' efficiency. Tutors developed their action plans for online teaching and highlighted the preparation of new materials, adoption of new technologies and skills. Based on the results of the transition from face-to-face to online anatomy teaching, there were detected five thematic items that were related to tutors' challenges. It was concluded that challenges that need to become a priority for tutors in online education concern mainly the special training courses, design of new models, video and/or online lectures, demonstration labs, practical classes, collegial contacts, technicians, IT-staff and colleagues support, consultation hours and communication. Future directions for tutors must be effective not only for increasing the quality of the Human Anatomy study process but also for the evolution of anatomy education.
\end{abstract}

Keywords: challenges, Covid-19, directions, online teaching, tutors.

\section{Introduction}

Digital Era has played a prominent role with informative and communication technologies in the COVID-19 pandemic period (Mukhtar, Javed, Arooj, \& Sethi, 2020). There were a lot of changes in different social, economical areas and fields, including medical studies (Saiyad, Virk, Mahajan, \& Singh, 2020). It created a new period in the anatomical education at the Department of Morphology of Rìga Stradiņš University (RSU).

This situation limited and excluded for medical students several traditional anatomical practices not only for models and specimens but also for access to cadavers. This situation was not easy for tutors and students during their teaching and learning process. It has increased the speed of transformation of roles of tutors 
Kazoka \& Pilmane, 2021. Remote Practical Anatomy Classes: New Challenges and Directions for Tutors

and students under the massive influence of digitalization (Guangul, Suhail, Khalit, \& Khidhir, 2020).

The relationship between the educational process and the following changes is not completely straightforward (Pei \& Wu, 2019). Traditional and routine work is changed with the need to adapt to online teaching (König, Jäger-Biela, \& Glutsch, 2020). Based on this, the creation of the new types of learning environments that are adaptable, flexible and suitable for multiple users has started to modify the physical space in teaching and learning (Shetty, Shilpa, Dey, \& Kavya, 2020).

In our department, new educational materials, the uploading of useful content, collected experiences, developed skills and the use of technologies in Human Anatomy practical classes stimulated changes in the roles of human tutors.

This article focuses on the tutors' transition from face-to-face to online anatomy teaching and their new strategies in the remote study process.

Thus, the aims of our study were to identify how tutors perceived the Covid-19 crisis with their personal experiences and solutions, and clarify their new challenges and directions.

\section{Material and Methods}

In spring-autumn 2020 tutors had to adapt to Covid-19 reality by restructuring their methods by teaching at the Department of Morphology. For this study, 15 tutors were interviewed and this method was used for data collection. The selection of tutors was based on an open and voluntary invitation. Importantly, their topics of practical classes related to all the major content offered in the Human Anatomy program from the first until third semesters.

Tutors were trained to teach study course using two available video communication platforms "Zoom" and "Panopto".

The study was designed to get answers to the following questions:

1) What are the new challenges of tutors in the remote study process of Human Anatomy?

2) What are the directions of tutors in the Human Anatomy course influenced by the Covid-19 situation?

An open-ended interview was the instrument used to collect data for the study. It was conducted in a one-on-one event and this process took approximately 10 to 15 minutes. The interviews were transcribed, and all answers of the tutors to open-ended questions were analyzed qualitatively, recoded depending on the thematic item and analyzed concerning the other answers.

The structure of the interview was developed concerning to the questions formulated for the study. The contents were made up of the experience characteristics of the Human Anatomy tutors based on remote practical classes, 
challenges and directions due to Covid-19. Factors that determined or affected challenges of the tutors were considered when formulating the questions in five thematic items: training in the use of digital platforms, tools; interactive course keeping; stressful situations decreasing; technical problems solving; help and support students. According to the number of answers, every item was divided into five categories ranging from 1 (the lowest) to 5 (the highest).

Directions of the tutors assessed during the study were related to self-concept and formation of the strategies.

\section{Results}

New challenges and directions of tutors found from the interviews were divided into five thematic items. Distribution of the categories in these items, according to the answers of the tutors, is shown in Table 1.

Table 1 Challenges and Directions of the Tutors in Remote Human Anatomy Study Course

\begin{tabular}{|c|c|c|c|c|c|}
\hline & \multicolumn{5}{|c|}{ Item } \\
\hline 胥 & $\begin{array}{l}\text { Training in the } \\
\text { use of digital } \\
\text { platforms, } \\
\text { tools }\end{array}$ & $\begin{array}{l}\text { Interactive course } \\
\text { keeping }\end{array}$ & $\begin{array}{c}\text { Stressful } \\
\text { situations } \\
\text { decreasing }\end{array}$ & $\begin{array}{l}\text { Technical } \\
\text { problems } \\
\text { solving }\end{array}$ & $\begin{array}{l}\text { Help and } \\
\text { support } \\
\text { students }\end{array}$ \\
\hline 1 & $\begin{array}{c}\text { basic } \\
\text { knowledge and } \\
\text { skills }\end{array}$ & $\begin{array}{c}\text { anatomical atlases, } \\
\text { 3D models, digital } \\
\text { images, different } \\
\text { online resources }\end{array}$ & $\begin{array}{l}\text { understandin } \\
\text { g of } \\
\text { unexpected } \\
\text { situations }\end{array}$ & $\begin{array}{l}\text { technical } \\
\text { knowledge } \\
\text { and skills }\end{array}$ & $\begin{array}{l}\text { records of the } \\
\text { video lectures }\end{array}$ \\
\hline 2 & $\begin{array}{l}\text { learning of the } \\
\text { platforms work }\end{array}$ & $\begin{array}{c}\text { “Complete } \\
\text { Anatomy” software }\end{array}$ & $\begin{array}{c}\text { controlling of } \\
\text { emotions }\end{array}$ & $\begin{array}{l}\text { equipped } \\
\text { working } \\
\text { space }\end{array}$ & $\begin{array}{c}\text { active learning } \\
\text { tools, different } \\
\text { exercises and } \\
\text { online } \\
\text { activities } \\
\end{array}$ \\
\hline 3 & $\begin{array}{l}\text { "Panopto" } \\
\text { tools and } \\
\text { options }\end{array}$ & $\begin{array}{l}\text { Powerpoint } \\
\text { presentations }\end{array}$ & $\begin{array}{l}\text { contacts with } \\
\text { IT-support }\end{array}$ & $\begin{array}{l}\text { platforms } \\
\text { problems }\end{array}$ & $\begin{array}{l}\text { “Complete } \\
\text { Anatomy” } \\
\text { integration }\end{array}$ \\
\hline 4 & $\begin{array}{l}\text { “Zoom” tools } \\
\text { and options }\end{array}$ & $\begin{array}{l}\text { sharing of prepared } \\
\text { electronic materials }\end{array}$ & $\begin{array}{l}\text { contacts with } \\
\text { students }\end{array}$ & $\begin{array}{l}\text { network } \\
\text { connection } \\
\text { problems } \\
\end{array}$ & $\begin{array}{l}\text { individual and } \\
\text { groups` work }\end{array}$ \\
\hline 5 & $\begin{array}{l}\text { special training } \\
\text { courses }\end{array}$ & $\begin{array}{l}\text { design of new } \\
\text { models, video } \\
\text { and/or online } \\
\text { lectures, } \\
\text { demonstration labs, } \\
\text { practical classes }\end{array}$ & $\begin{array}{l}\text { collegial } \\
\text { contacts }\end{array}$ & $\begin{array}{l}\text { technicians, } \\
\text { IT-staff and } \\
\text { colleagues } \\
\text { support }\end{array}$ & $\begin{array}{c}\text { consultation } \\
\text { hours and } \\
\text { communication }\end{array}$ \\
\hline
\end{tabular}


Kazoka \& Pilmane, 2021. Remote Practical Anatomy Classes: New Challenges and Directions for Tutors

As presented in Table 1, the answers to the questions in the thematic item "Training to have an understanding of using digital platforms and tools" were codified into five categories.

In the beginning, we asked tutors about their understanding of using digital platforms and tools teaching online practical classes. The answers of the 1st category represent that realization of remote practical classes required tutors to have a basic knowledge and skills in using digital platforms of teaching. Several tutors indicated a limited experience of this type of teaching, including very basic knowledge and skills in the understanding of computers and their possibilities for using different digital platforms.

The 2nd category refers to the learning of the platform's work. Trying out new platforms, digital tools and methods were appreciated only by some tutors.

The 3rd and 4th categories represent the answers about tutors' used type of digital platform in the study process during the lockdown. Tutors used two platforms that the best suited to longer, practical classes teaching or the best suited to shorter, lectures teaching. "Panopto" and "Zoom" platforms were used in different ways, depending on tutors' knowledge, skills, needs of their students and prepared materials. At the beginning of the pandemic situation, tutors had a poor experience in the use of these platforms.

In the lower number of the tutors' answers, the use of "Panopto" was indicated only for lectures and video lectures.

Slowly and step by step tutors' attention has been transferred to "Zoom" teaching functionalities. Tutors' answers showed that due to its relative stability, delivering of the practical classes in real-time, more easiest operation with available tools and simple interface, "Zoom" was more intensive used for practical classes during the pandemic period.

The 5th category with the most answers included the participation of tutors in special training courses that were offered by specialists of the Information Technologies (IT) Department and the Pedagogical Development Center at RSU. Tutors studied the latest updates of different platforms and received digital competencies for the conduction of the remote study process.

The big challenge for tutors was to hold an active Human Anatomy teaching and learning where students didn't show their faces in practical class and/or lecture. As contained in Table 1, the second item, including five categories, was focused on "Keeping online anatomy classes more interactive".

The use of anatomical atlases, 3D models, digital images and different online resources is a category that refers to the 1st category with actions for more interactive practical classes, including more intensive participation of students during that time. Their availability was considered as an advantage only by onehalf of the tutors' answers. There existed variations between methods and types 
of remote activities organized, from pre-recorded materials to online digital exercises.

Following the analysis of the answers, the 2nd and 3rd categories represent that "Complete Anatomy" software and Powerpoint presentations were also used by tutors through live streaming, group works, homework and discussions.

Another important or 4th category, according to obtained answers, underlines that tutors started to share with students all prepared electronic materials via the same platform. These materials were prepared by the tutor alone or together with others, and there were shared a lot of new or updated previously existed materials. Some tutors' answers indicated that they were not satisfied with their materials sharing for others.

The category with the most answers represents that tutors started to develop the design of new models and video lectures, online lectures, demonstration labs (DemoLabs) and practical classes in Human Anatomy.

The third item with five categories was to discover how tutors define "Stressful situations decreasing" (Table 1).

The group of tutors regarding the understanding of unexpected situations comprised the answers about the behavior of students during practical classes, including noisiness, hyperactivity, lack of interest, unpreparedness for practical class and different expressions of their emotions.

The 2nd category of the answers, chosen by tutors, represented the controlling of emotions. In interviews, tutors described some factors that increased stress, including their health, worries about technical equipment, teaching resources and tools. It was important to control speakers' (tutor and/or student) roles, to use different available digital possibilities of the platforms, backgrounds, whiteboard, set up break out groups and the ability to have several hosts.

More specifically, tutors noted that contacts with IT and its support were important in remote practical classes. At the beginning of the pandemic situation a high level of stress was detected by tutors due to feeling that they were unsupported by technical specialists. After several days of training, support from technicians and finished special digital platforms using courses tutors indicated that some situations were less stressful than in the previous period time.

The categories with the most answers included stressful situations decreasing related to contacts. Tutors started to cooperate more closely together with students and each other, forming teamwork via virtual contacts and/or calls. Feedback and collaboration stimulated the development of adaption and control of different situations and it allowed tutors to manage their practical classes more effectively and less stressful. 
Kazoka \& Pilmane, 2021. Remote Practical Anatomy Classes: New Challenges and Directions for Tutors

The fourth item included aspects related to the tutor's "Technical problems solving”.

As shown in Table 1, in the 1st category, there were included answers about technical knowledge and skills. In the beginning, reality was made clearer and tutors struggled with part of the new problems. During some weeks and/or months they developed an understanding of their level of knowledge and skills in this pandemic situation and time of crisis and started to think about how to solve part of upcoming problems in planning, the realization of their work with computers and work with students. Slowly and step by step tutors started managed their activities and performances, discovered new methods and possibilities in the remote study process of Human Anatomy.

After careful analysis of answers, another important category was related to equipped working space. Missing some equipment (updated and powerful computer, camera, microphone) and not working properly current technologies didn't allow the tutors to use technologies to their full capacities and to provide teaching in high quality.

In the 3rd category, there were included answers about platforms problems. Better quality for larger capacity teaching sessions was found for the "Zoom" platform, comparing with larger capacity teaching sessions for "Panopto". More disrupted sessions and some technical barriers were detected directly for using of "Panopto" platform. In both cases, these platforms provided strong support in the remote study process and reformed several existed teaching methods during the pandemic period.

Problems that were related to the network connection included access to the Internet, unstable connection, signal loss, interruptions or disconnections. Like the primary options, anatomy tutors were used more often in live lectures and practical classes. These problems made a lot of technical difficulties for tutors in their work. Besides this, several students indicated that in their environments they had no adequate computer or other digital device, problems with internet access and signal loss.

Most answers were included in the fifth category, and all of them were related to the support of the tutors from technicians, IT-staff and colleagues at RSU. There were provided special consultations, events, resources and courses for tutors in assisting with their creating and implementing technical knowledge, skills and solutions of the problems in the remote study process. Technicians and colleagues from IT-staff shared their skills with tutors, supported and helped to find them the best solutions in teaching during the Covid-19. Help and/or support by courses and programs coordinators, mentors and students or leaders of groups and semesters were helpful as well. 
Again as presented in Table 1, the fifth item discovered how tutors were involved in "Helping students and supporting them".

The lowest number of answers received for records of the video lectures. Tutors used the recording feature in "Panopto" and created video lectures that were uploaded for their students and for later watching in the e-studies. Students were free to replay the videos, pause or slow them down to help them understand and study the content of the material better.

The 2nd category, chosen by a group of tutors, represented answers about the use of active learning tools, different exercises and online activities and their use for digital collaboration. In the regular class time on "Zoom" tutors used plastic anatomical models, online resources and/or three-dimensional (3D) printed models. According to this, students were guided by their tutors in different anatomical topics, structures and regions of the human body.

In the Covid-19 pandemic situation tutors and students lost access to dissections and optimal educational tools: real materials, specimens, plastic models and cadavers. Based on this, a very beneficial tool or software "Complete Anatomy" was integrated by tutors into the Human Anatomy course design and used for students through the study process. A few tutors still underline that human cadaveric dissection can not be replaced by any virtual software or another style of learning.

The next category was related to tutors' individual and groups' work. Focusing on answers, tutors used live "Zoom” practical classes to answer questions about learned materials, to detect needs, knowledge of students or to explain more complicated anatomical structures and topics.

Most answers were received for consultation hours and communication. The lack of interaction or direct communication with students developed the restucturing of tutors' regular work. In the period of remote practical classes, all tutors were scheduling regular "consultation hours" that allowed students to ask questions in voice or chat with tutors and classmates in groups.

\section{Discussion}

The current study reported Human Anatomy tutors' personal experiences and solutions remote practical classes in the Covid-19 crisis, and interpreted their new challenges and directions.

In the time of Covid-19, many educators around the countries and the world started to look at how to integrate "new normal" in basic medical studies (Ferrel \& Ryan, 2020). It has been reported that the pandemic situation affected anatomy teaching and learning differently, and it provided an opportunity for self-study (Mahdy, 2020). Results of our study showed that all tutors changed various methods and styles in their Human Anatomy study process, remodeled the design 
Kazoka \& Pilmane, 2021. Remote Practical Anatomy Classes: New Challenges and Directions for Tutors

of practical classes and adapted to the current situation, and this was in agreement with other medical study done by Rose (2020).

Remote education, especially without the right technologies and tools for it, can be difficult and complicated for tutors (Muilenburg \& Berge, 2001). In our study tutors who were interested in developing themselves studied to get new knowledge and improve their teaching skills. The majority of the tutors started to study how to work with different platforms and visited distant training courses, seminars, webinars and meetings with IT specialists. These findings were confirmed also in the work of O’Doherty et al. (2018). The authors noted that there was also a strong need for inter-faculty cooperation and institutional support.

To better understand the disputes from the sources, it is necessary to analyze the changes in tutors' concerns on digital platforms during the pandemic period (Dhawan, 2020). Two platforms "Zoom" and "Panopto" were used by our tutors for support of video communications. At the beginning of the use of these platforms tutors indicated several technical problems (access, updates, etc.) or limits in the adequate ability to access the platform. These problems chose the main platform for practical classes and lectures. Most popular for our tutors was "Zoom" with several benefits. The use of "Zoom" was not surprising, because it has been the standard platform at RSU for organizing contents of study courses and communicating between students and tutors. One part of the selection criteria for tutors was the quality of audio and video, but the other part of the choice of platform was the quality of recording of practical classes and lectures. Besides, recordings of lectures and DemoLabs allow students to revise teaching materials and content of the anatomical topics.

Our study is also in line with another study that the interactive course keeping and design of practical classes depend on individual tutor's creativity (Pozo-Rico, Gilar-Corbí, Izquierdo, \& Castejón, 2020). At the beginning of the pandemic period, the majority of tutors experimented and transformed the practical classes, according to their design of teaching. Tutors started to plan practical classes that were filled with information from presentations, videos and supported by visualization of plastic anatomical models. Some of them chose the style and tools for the better and more interactive explanation of materials and more longer focusing of students attention. Tutors' input comprised work of weeks and months. Besides this, some tutors started to feel that the students didn't understand practical details and didn't detect anatomical structures without touching and dimensional observation.

Online classes and adaption to virtual education give new experiences and discover positive and negative tendencies (Simamora, 2020). Due to this crisis, our tutors also become in front of stressful situations decreasing. We found out that collegial contacts and contacts with students were the most often answers of tutors about how to decrease stressful situations. Meetings in different distant 
platforms, video calls, phone contacts and regular e-mails comprised one part of the day or changed the regular rhythm of life, and these findings are supported by the results of another study (Kim, 2020).

For the teaching and learning process, for the explanation and understanding of the anatomical topics with their content, tutors and students must have qualitative equipment and online connectivity (Agarwal \& Kaushik, 2020). In the beginning transformation of the content of the Human Anatomy study course to the virtual environment, including technical difficulties, tutors made more questions than answers. According to our results, the majority of the tutors underlined that support of technicians, IT-staff and colleagues are essential for the success of remote teaching and learning. These results are in line with the view of Al-Balas et al. (2020).

Tutors should be interested in students as young and future specialists with medical skills and medical knowledge (Gaur et al., 2020). In our study tutor's communication, development of this type of skills and contacts with students in a virtual environment comprised much more time than it was in a traditional environment. Shim and Lee (2020) affirmed that tutors were involved to switch to a teaching type that was more student-centered. According to this, it was very important for our tutors to guide their students in learning and understanding of the anatomy of the human body and its details not only in remote practical classes but also afterward. In a study by Dumford and Miller (2018), there was found out that the communication and interaction between dominant tutors and supplemented participation of students don't show all needs of teaching.

We understand that lack of dissections and different anatomic specimens excluded the possibility to get practical skills and, according to this, there will be new and post-Covid 19 problems for tutors and current students in the future. Thereby, different mixed and combined methods are needed for the educational process (Almaiah, Al-Khasawneh, \& Althunibat, 2020).

In our department, remote practical classes have relatively new concepts. Therefore, there is a need for new and updated format medical educators, and with regular analysis of their challenges and directions.

\section{Conclusions}

Remote practical classes of the Human Anatomy at the Department of Morphology were found to exhibit several tutors' challenges which are related to the continuation and realization of the study process in the Covid-19 situation. In this regard, tutors must develop various skills to manage their use of digital platforms, tools and to keep the interactive courses, decrease stressful situations, solve technical problems, help and support students. 
Kazoka \& Pilmane, 2021. Remote Practical Anatomy Classes: New Challenges and Directions for Tutors

Challenges that need to become a priority for tutors in online education concern mainly the special training courses, design of new models, video and/or online lectures, demonstration labs, practical classes, collegial contacts, technicians, IT-staff and colleagues support, consultation hours and communication.

Therefore, it is important that tutors can develop their strategic directions in the future that are effective not only for increasing the quality of the Human Anatomy study process and its' special format without cadaveric dissections in the online, digital environment, assessments, time investment and combination of traditional and remote methods but also for the evolution of anatomy education, including the development of tutors' digital competencies, managing of current equipment, integration and adoption of technologies for the teaching of anatomical knowledge and practical skills, cooperation between departments, redesigning or new curriculum development for current or next years periods.

\section{Acknowledgements}

We would like to thank all Human Anatomy tutors for their time, experience and involvement in this study.

\section{References}

Agarwal, S., \& Kaushik, J. S. (2020). Student's Perception of Online Learning during COVID Pandemic. The Indian Journal of Pediatrics, 87(7), 554. DOI: 10.1007/s12098-02003327-7

Al-Balas, M., Al-Balas, H. I., Jaber, H. M., Obeidat, K., Al-Balas, H., Abarajooh, E. A., AlTaher, R., \& Al-Balas, B. (2020). Distance learning in clinical medical education amid COVID-19 pandemic in Jordan: current situation, challenges, and perspectives. BMC Medical Education, 20, 341. DOI: https://doi.org/10.1186/s12909-020-02257-4

Almaiah, M. A., Al-Khasawneh, A., \& Althunibat, A. (2020). Exploring the critical challenges and factors influencing the E-learning system usage during COVID-19 pandemic. Education and Information Technologies, 25, 5261-5280. DOI: https://doi.org/10.1007/s10639-020-10219-y

Dhawan, S. (2020). Online Learning: A Panacea in the Time of COVID-19 Crisis. Journal of Educational Technology Systems, 49(1), 5-22. DOI: https://doi.org/10.1177/ 0047239520934018

Dumford, A. D., \& Miller, A. L. (2018). Online learning in higher education: Exploring advantages and disadvantages for engagement. Journal of Computing in Higher Education, 30(3), 452-465. DOI: https://doi.org/10.1007/s12528-018-9179-z

Ferrel, M. N., \& Ryan, J. J. (2020). The Impact of COVID-19 on Medical Education. Cureus, 12(3), e7492. DOI: 10.7759/cureus.7492

Gaur, U., Majumder, M. A., Sa, B., Sarkar, S., Williams, A., \& Singh, K. (2020). Challenges and Opportunities of Preclinical Medical Education: COVID-19 Crisis and Beyond. SN 
Comprehensive Clinical Medicine, 2, 1992-1997. DOI: https://doi.org/10.1007/s42399020-00528-1

Guangul, F. M., Suhail, A. H., Khalit, M. I., \& Khidhir, B. A. (2020). Challenges of remote assessment in higher education in the context of COVID-19: a case study of Middle East College. Educational Assessment, Evaluation and Accountability, 21 October, 1-17. DOI: https://doi.org/10.1007/s11092-020-09340-w

Kim, J. (2020). Learning and Teaching Online During Covid-19: Experiences of Student Teachers in an Early Childhood Education Practicum. International Journal of Early Childhood, 52, 145-158. DOI: 10.1007/s13158-020-00272-6

König, J., Jäger-Biela, D. J., \& Glutsch, N. (2020). Adapting to online teaching during COVID19 school closure: teacher education and teacher competence effects among early career teachers in Germany. European Journal of Teacher Education, 43(4), 608622, DOI: 10.1080/02619768.2020.1809650

Mahdy, M. (2020). The Impact of COVID-19 Pandemic on the Academic Performance of Veterinary Medical Students. Frontiers in Veterinary Science, 7, 594261. DOI: https://doi.org/10.3389/fvets.2020.594261

Muilenburg, L., \& Berge, Z. L. (2001). Barriers to Distance Education: A Factor-Analytic Study. American Journal of Distance Education, 15(2), 7-22. DOI: 10.1080/08923640109527081

Mukhtar, K., Javed, K., Arooj, M., \& Sethi, A. (2020). Advantages, Limitations and Recommendations for online learning during COVID-19 pandemic era. Pakistan Journal of Medical Sciences, 36(COVID19-S4), COVID19-S27-S31. DOI: https://doi.org/ 10.12669/pjms.36.COVID19-S4.2785

O’Doherty, D., Dromey, M., Lougheed, J., Hannigan, A., Last, J., \& McGrath, D. (2018). Barriers and solutions to online learning in medical education - an integrative review. BMC Medical Education, 18,130. DOI: https://doi.org/10.1186/s12909-018$1240-0$

Pei, L., \& Wu, H. (2019). Does online learning work better than offline learning in undergraduate medical education? A systematic review and meta-analysis. Medical Education Online, 24(1), 1666538. DOI: https://doi.org/10.1080/10872981. 2019.1666538

Pozo-Rico, T., Gilar-Corbí, R., Izquierdo, A., \& Castejón, J. L. (2020). Teacher Training Can Make a Difference: Tools to Overcome the Impact of COVID-19 on Primary Schools. An Experimental Study. International Journal of Environmental Research and Public Health, 17(22), 8633. DOI: 10.3390/ijerph17228633

Rose, S. (2020). Medical Student Education in the Time of COVID-19. JAMA, 323(21), 21312132. DOI: $10.1001 /$ jama.2020.5227

Saiyad, S., Virk, A., Mahajan, R., \& Singh, T. (2020). Online teaching in medical training: Establishing good online teaching practices from cumulative experience. International Journal of Applied Basic Medical Research, 10, 149-55. DOI: https://www.ijabmr.org/ text.asp?2020/10/3/149/289474

Shetty, S., Shilpa, C., Dey, D., \& Kavya, S. (2020). Academic Crisis During COVID 19: Online Classes, a Panacea for Imminent Doctors. Indian Journal of Otolaryngology and Head \& Neck Surgery, 17 October, 1-5. DOI: 10.1007/s12070-020-02224-X

Shim, T. E., \& Lee, S. Y. (2020). College students' experience of emergency remote teaching due to COVID-19. Children and Youth Services Review, 119, 105578. DOI: https://doi.org/10.1016/j.childyouth.2020.105578 
Kazoka \& Pilmane, 2021. Remote Practical Anatomy Classes: New Challenges and Directions for Tutors

Simamora, R. M. (2020). The Challenges of online learning during the COVID-19 pandemic: An essay analysis of performing arts education students. Studies in Learning and Teaching, 1(2), 86-103. DOI: https://doi.org/10.46627/silet 